\title{
DIVERSIDADE E ESTRUTURA DE ESPÉCIES ARBÓREAS EM ÁREA ALAGÁVEL DO MUNICÍPIO DE LONDRINA, SUL DO BRASIL ${ }^{1}$
}

\author{
Edmilson Bianchini ${ }^{2,3}$ \\ Raquel Silveira Popolo \\ Marilda Carvalho Dias ${ }^{2}$ \\ José Antonio Pimenta ${ }^{2}$
}

Recebido em 15/08/2002. Aceito em 29/01/2003

RESUMO - (Diversidade e estrutura de espécies arbóreas em área alagável do município de Londrina, Sul do Brasil). Um levantamento fitossociológico em área alagável do Parque Estadual Mata dos Godoy, Londrina, PR, sul do Brasil ( $23^{\circ} 27^{\prime} \mathrm{S}$ e $\left.51^{\circ} 15^{\prime} \mathrm{W}\right)$ determinou a diversidade e a estrutura das espécies arbóreas. O levantamento foi realizado em 0,5 ha utilizando-se 50 parcelas de $10 \mathrm{~m} \times 10 \mathrm{~m}$, tendo-se como critério de inclusão o perímetro mínimo a altura do peito de $15 \mathrm{~cm}$. Para cada espécie foram calculadas a densidade, a frequiência e a dominância. Foram amostrados 912 indivíduos vivos e 58 mortos em pé. Os indivíduos vivos se distribuíram em 26 famílias, 49 gêneros e 64 espécies, e o índice de diversidade de Shannon $(3,44)$ foi menor que de outras áreas do Parque. Leguminosae e Myrtaceae apresentaram o maior número de espécies, enquanto que Nectandra megapotamica (Spreng.) Mez, Chrysophyllum gonocarpum (Mart. \& Eichler), Actinostemon concolor (Spreng.) Müll. Arg., Ruprechtia laxiflora Meisn. e Trichilia catigua A. Juss. apresentaram os maiores valores de importância neste ambiente. $\mathrm{O}$ alagamento está relacionado com a menor diversidade e com a estrutura da área, onde as espécies com estratégias mais eficientes tornam-se dominantes e caracterizam esta comunidade.

Palavras-chave - áreas alagáveis, classes de tamanho, riqueza de espécies, fitossociologia, sul do Brasil

\begin{abstract}
Diversity and structure of a tree species community in flooded area in the municipality of Londrina, Southern Brazil). A phytosociological study was developed in flooded area of the Mata dos Godoy State Park, municipality of Londrina, southern Brazil $\left(23^{\circ} 27^{\prime} \mathrm{S}\right.$ and $\left.51^{\circ} 15^{\prime} \mathrm{W}\right)$ in order to determine the diversity and the structure of tree species. Fifty $10 \mathrm{~m} \times 10 \mathrm{~m}$ plots $(0,5 \mathrm{ha})$ were used to sample trees with GBH (girth at breast height $) \geq 15,0 \mathrm{~cm}$. Density, frequency and dominance parameters were calculated for each species. In this area 912 living and 58 dead individuals were sampled. The living individuals were distributed in 26 families, 49 genera and 64 species. The value of the Shannon's diversity index was 3,44. The families with the highest species number were Leguminosae and Myrtaceae, while Nectandra megapotamica (Spreng.) Mez, Chrysophyllum
\end{abstract}

\footnotetext{
1 Auxílio CNPq, processo 420039/00-7

2 Departamento de Biologia Animal e Vegetal, Centro de Ciências Biológicas, Universidade Estadual de Londrina. C. Postal 6001, CEP 86051-970, Londrina, PR, Brasil.

3 Autor para correspondência (bianchi@uel.br)
} 
gonocarpum (Mart. \& Eichler), Actinostemon concolor (Spreng.) Müll. Arg., Ruprechtia laxiflora Meisn. and Trichilia catigua A. Juss. were the most important species in this area. The less diversity and structure of this area is related to flooding and the species adapted to this environment are recruited in higher abundance.

Key words - flooded area, phytosociology, size classes, southern Brazil, species richness

\section{Introdução}

A fisionomia, a composição específica e a estrutura de uma formação vegetal são potencialmente influenciadas e decorrentes de importantes mudanças temporais e espaciais de qualquer condição ambiental. Variação em um dos fatores do meio, como por exemplo, freqüência de inundações, pode resultar em alteração no comportamento de determinadas populações (Rodrigues \& Sheperd 2000).

As florestas ciliares apresentam alta diversidade florística em resposta à alta heterogeneidade do ambiente, provocada por diferenças na topografia, na idade da formação, nas características edáficas e na flutuação do lençol freático (Rodrigues \& Leitão-Filho 2000). Em determinadas áreas que apresentam diferenças microtopográficas, a vegetação alterna-se desde espécies que ocorrem em depressões e que toleram longos períodos de alagamento até espécies de ambiente mésico que ocorrem em sítios mais altos (Salo et al. 1986; Mertes et al. 1995). Levantamentos fitossociológicos realizados em remanescentes florestais da bacia do rio Tibagi, Estado do Paraná, sul do Brasil, apresentaram índices de diversidade de Shannon (H') de 3,6 a 4,2 (Soares-Silva \& Barroso 1992; Soares-Silva et al. 1992; Silva et al. 1995; Nakajima et al. 1996; Dias et al. 1998; Soares-Silva et al. 1998), exceto para um remanescente de várzea que apresentou $\mathrm{H}^{\prime}=2,2$ (Silva et al. 1992), sugerindo menor diversidade de espécies para as áreas sujeitas a inundações. Portanto, a duração do alagamento tem forte impacto na diversidade de espécies (Joly 1991; Ferreira \& Stohlgren 1999) e as espécies dominantes em florestas inundáveis podem não ocorrer nas áreas mais altas (Stevenson et al. 1999).
Entre os remanescentes de floresta estacional semidecidual do Paraná, destaca-se o Parque Estadual Mata dos Godoy (PEMG), localizado na bacia do rio Tibagi. Este parque possui área de 680ha, sendo cerca de 500ha de floresta primária (Bianchini et al. 2001). Dado ao alto grau de degradação ambiental da região norte do Paraná (Silva \& Soares-Silva 2000), este parque assume importância fundamental como local de estudo e como banco de germoplasma para futuros projetos de recuperação ambiental nesta região.

Três estudos fitossociológicos foram realizados no PEMG. Soares-Silva \& Barroso (1992) realizaram levantamento florístico e fitossociológico em uma área da porção norte (espigão) e encontraram um índice de diversidade de Shannon (H') de 3,69. Aspidosperma polyneuron Müll. Arg. e Meliaceae foram, respectivamente, a espécie e a família de maiores valores de importância (VI), destacando-se as altas densidades de Trichilia clausseni C. DC. e Euterpe edulis Mart. Silveira (1993), estudando uma toposeqüência da floresta, encontrou um H' = 3,69 para a área de encosta, com Parapiptadenia rigida e Mimosaceae apresentando os maiores VI. Soares-Silva et al. (1998) encontraram um H' $=3,9$ para a floresta ciliar, sendo que Nectandra megapotamica apresentou o maior VI.

A escassez de informações sobre áreas alagáveis no país e a inexistência de estudos em áreas alagáveis na região norte do Paraná ressalta a importância de estudos nestas áreas, visando conhecer a estrutura e o funcionamento destas comunidades. Os projetos de recuperação do ambiente ciliar terão maiores probabilidades de sucesso se for considerada toda a diversidade de habitats destas áreas, as 
espécies típicas de cada habitat e os padrões estruturais da comunidade.

As diferenças topográficas encontradas na floresta ciliar do PEMG, a maior abundância de indivíduos de algumas espécies nas áreas alagáveis (observações de campo) e uma diversidade provavelmente menor nas áreas alagáveis em relação à floresta ciliar motivaram o desenvolvimento deste estudo, visando conhecer com mais detalhes a comunidade arbórea de áreas alagáveis. Levantou-se as seguintes questões: quais são e como estão estruturadas as espécies arbóreas que ocorrem nas áreas alagáveis do PEMG? Suas principais espécies estão se regenerando? Os dados permitiram avaliar, também, a regeneração da comunidade, utilizando-se a estrutura de tamanho das principais espécies.

\section{Material e métodos}

O Parque Estadual Mata dos Godoy (PEMG) localiza-se no município de Londrina, PR, sul do Brasil (coordenadas da sede: $23^{\circ} 27^{\prime} \mathrm{S}$ e $51^{\circ} 15^{\prime} \mathrm{W}$ ), com altitude variando de $600 \mathrm{~m}$ na face norte ("espigão") a 500m.s.m. na face sul (fundo do vale). É circundado por terras cultivadas, pastos, áreas florestadas e reflorestadas e é delimitado ao sul pelo ribeirão dos Apertados, único curso de água permanente.

Segundo a classificação de Köppen, o clima da região é do tipo Cfa - clima subtropical úmido. A temperatura média anual é de $20,9^{\circ} \mathrm{C}$. O mês de janeiro é o mais quente do ano (média de $23,8^{\circ} \mathrm{C}$ ) e o mais frio é o mês de junho (média de $\left.16,6^{\circ} \mathrm{C}\right)$. A precipitação média anual é cerca de $1.600 \mathrm{~mm}$, sendo que a pluviosidade durante o verão (dezembro $=230 \mathrm{~mm}$ ) é cerca de duas vezes maior que no inverno (agosto $=51 \mathrm{~mm}$ ), caracterizando duas estações bem definidas quanto à precipitação (Silva \& Soares-Silva 2000; Bianchini et al. 2001). O ribeirão dos Apertados, por ser muito sinuoso, forma vários terraços, que na época das chuvas (dezembro-janeiro) são alagados. A inundação pode ocorrer pelo extravasamento do rio ou pela elevação do lençol freático. No primeiro caso, a correnteza formada pode retirar a serapilheira e o banco de sementes, arrancar plantas jovens de alguns locais ou soterrá-las, devido à deposição de sedimentos em outros, o que tem forte implicações na dinâmica da comunidade.

O solo dos terraços é classificado como Latossolo Roxo Hidromorfizado na Base, revelando-se bastante argiloso, medianamente ácido, bem drenado superficialmente e mal drenado em profundidades inferiores a $50 \mathrm{~cm}$, devido à presença do lençol freático (Silveira 1993).

Para o estudo fitossociológico da comunidade da área alagável utilizou-se o método de parcelas. Como estas áreas no Parque são restritas e descontínuas por ocorrerem nos terraços, foram alocadas 50 parcelas divididas em 3 grupos de 16, 18 e 16 parcelas contíguas, respectivamente. A área estabelecida de cada parcela foi de $100 \mathrm{~m}^{2}(10 \mathrm{~m} \times 10 \mathrm{~m})$, totalizando $5.000 \mathrm{~m}^{2}$ (0,5ha).

O critério mínimo de inclusão dos indivíduos amostrados foi de $15 \mathrm{~cm}$ de perímetro do tronco à altura do peito (PAP). Os indivíduos amostrados foram identificados com plaquetas metálicas numeradas, sendo registrados a altura total, estimada visualmente por comparação com a extensão telescópica de uma tesoura de poda alta de 7,5m, e o perímetro (PAP), medido com auxílio de fita métrica. Os exemplares coletados foram preparados de acordo com a metodologia usual (Mori et al. 1985), identificados por comparação com exsicatas do Herbário da Universidade Estadual de Londrina (FUEL) e, quando necessário, com o auxílio de especialistas. Os nomes de famílias seguem o sistema de Cronquist (1981) considerando a família Leguminosae "senso amplo".

Os cálculos fitossociológicos seguiram Mueller-Dombois \& Ellenberg (1974) e foram realizados através do programa FITOPAC (Shepherd 1996). Determinou-se o índice de diversidade de Shannon - H', o índice de 
equabilidade de Pielou - J' (Ludwig \& Reynolds 1988) e o índice de similaridade de Jaccard - C (Brower \& Zar 1984) com os demais estudos efetuados no Parque (Soares-Silva \& Barroso 1992; Silveira 1993; Soares-Silva et al. 1998) e com o levantamento realizado em uma várzea do rio Tibagi (Silva et al. 1992).

Para as populações das espécies com maiores valores de importância (VI) determinou-se a estrutura de tamanho (classes de diâmetro) e o padrão espacial na escala de $10 \mathrm{~m} \times 10 \mathrm{~m}$. A análise do padrão espacial das populações foi realizada utilizando-se o Coeficiente de Dispersão (CD), obtido pela razão variância/média (Brower \& Zar 1984). Quando o $C D=1$, o padrão espacial de distribuição da população é aleatório; $C D>1,0$ padrão é agregado; $\mathrm{CD}<1$, o padrão é uniforme. Para testar se os valores do CD diferiam significativamente da unidade, utilizou-se o teste $\mathrm{t}$ (Brower \& Zar 1984).

\section{Resultados e discussão}

O inventário da área alagável do PEMG registrou 912 indivíduos vivos e 58 mortos em pé, representando $6 \%$ do total. Os espécimes vivos se distribuem em 26 famílias, 49 gêneros e 64 espécies (Tab. 1 e 2). Comparando-se os estudos realizados no parque verificou-se maior número de famílias e de espécies na floresta da porção norte, enquanto que a floresta ciliar

Tabela 1. Relação das famílias e espécies vegetais arbóreas em ordem alfabética, com seus respectivos nomes populares, amostradas em área alagável do Parque Estadual Mata dos Godoy, Londrina, PR.

\section{Família/Espécie}

\section{ACANTHACEAE}

Justicia brasiliana Roth

ACHATOCARPACEAE

Achatocarpus pubescens $\mathrm{C}$. H. Wright

APOCYNACEAE

Tabernaemontana catharinensis (A.DC.) Miers

BORAGINACEAE

Patagonula americana $\mathrm{L}$.

COMBRETACEAE

Terminalia sp.

ELAEOCARPACEAE

Sloanea monosperma Vell.

EUPHORBIACEAE

Actinostemon concolor (Spreng.) Müll. Arg.

Alchornea triplinervia (Spreng.) Müll. Arg.

Croton floribundus Spreng.

Sapium glandulatum (Vell.) Pax

Sebastiania commersoniana (Baill.) L. B. Sm. \& Downs

FLACOURTIACEAE

Banara tomentosa Clos

Casearia decandra Jacq.

Casearia sylvestris $\mathrm{Sw}$.

\section{LAURACEAE}

Nectandra megapotamica (Spreng.) Mez

Ocotea dyospirifolia (Meisn.) Mez

Ocotea indecora Schott

Ocotea puberula (Rich.) Nees
Nome popular

junta-de-cobra-vermelha

cabo-de-lança, galinheiro

leiteiro

guajuvira

sapopema

laranjeira-do-mato

jangada, jangadeiro, tapiá-guaçu

capixingui

leiteiro-graúdo

branquilho, leiteiro

guassatunga-preta

guassatunga

café-de-bugre, erva-de-lagarto

canelinha, canela-preta

canela

canela

canela-gosmenta, canela-guaocá, canela-sebo 
Tabela 1 (continuação)

Família/Espécie

LEGUMINOSAE - Caesalpinioideae Bauhinia longifolia (Bong.) Steud.

LEGUMINOSAE - Mimosoideae Acacia polyphylla DC.

Inga marginata Willd.

Parapiptadenia rigida (Benth.) Brenan

LEGUMINOSAE - Papilionoideae

Dalbergia frutescens (Vell.) Britton

Holocalyx balansae Micheli

Lonchocarpus campestris Mart. ex Benth.

Lonchocarpus muehlbergianus Hassl.

Machaerium paraguariense Hassl.

Machaerium stipitatum (DC.) Vogel

Myrocarpus frondosus M.Allemão

LOGANIACEAE

Strychnos brasiliensis (Spreng.) Mart.

MELIACEAE

Guarea macrophylla Vahl

Trichilia casaretti C. DC.

Trichilia catigua A. Juss.

Trichilia clausseni C. DC.

Trichilia elegans A. Juss.

MORACEAE

Sorocea bonplandii (Baill.) W.C. Burger, Lanj. \& Wess. Boer MYRSINACEAE

Myrsine aff. loefgrenii (Mez) Otegui

MYRTACEAE

Campomanesia guaviroba (DC.) Kiaersk.

Campomanesia guazumifolia (Cambess.) O. Berg

Campomanesia xanthocarpa $\mathrm{O}$. Berg

Eugenia cf. moraviana O. Berg

Eugenia neoverrucosa Sobral

Eugenia ramboi D. Legrand

Eugenia repanda $\mathrm{O}$. Berg

Eugenia uniflora L.

Myrciaria floribunda (West ex Willd.) O. Berg

Plinia rivularis (Cambess.) Rotman

NYCTAGINACEAE

Bougainvillea spectabilis Willd.

Pisonia aculeata L.

PHYTOLACCACEAE

Phytolacca dioica $\mathrm{L}$.

PICRAMNIACEAE

Picramnia ramiflora $\mathrm{Planch}$.

POLYGONACEAE

Ruprechtia laxiflora Meisn.

RUBIACEAE

Alseis floribunda Schott

Simira corumbaensis (Standl.) Steyerm.

RUTACEAE

Balfourodendron riedelianum (Engl.) Engl.
Nome popular

pata-de-vaca, unha-de-vaca

monjoleiro

ingá-dedo, ingá-feijão

angico-vermelho, gurucaia

imbira

alecrim-de-campina

angelim-bravo, rabo-de-macaco

feijão-cru, timbó

jacarandá, sapuvão

farinha-seca, sapuva

cabreúva, óleo-pardo

anzol-de-lontra

ataúba

catiguá-vermelho

catiguá

catiguá

pau-de-ervilha

capiricica, cincho

guariroba-de-árvore

capoteira, sete-capotes

guabirobeira

araçá

batinga-branca

pitangueira

guamirim

primavera, três-marias

maria-mole, umbu, cebolão

cedrinho, cedrinho

farinha-seca, viraru

pau-marfim 
Tabela 1 (continuação)

\begin{tabular}{ll}
\hline Família/Espécie & Nome popular \\
\hline SAPINDACEAE & \\
Allophylus guaraniticus (A. St.-Hil.) Radlk. & vacum \\
Cupania vernalis Cambess. & camboatá, cuvatã \\
miguel-pintado & \\
MAtayba elaeagnoides Radlk. & aguai-da-serra, guatambu-de-leite \\
Chrysophyllum gonocarpum (Mart. \& Eichler) Engl. & aguai-vermelho \\
Chrysophyllum marginatum (Hook. \& Arn.) Radlk. & aguai-açu \\
Pouteria beaurepairei (Glaz. \& Raunk.) Baehni & \\
SOLANACEAE & \\
Vassobia breviflora (Sendtn.) Hunz. & \\
TILIACEAE & açoita-cavalo \\
Luehea divaricata Mart. & \\
URTICACEAE & \\
Bohemeria caudata Sw. & \\
\hline
\end{tabular}

apresentou maior número de gêneros (Tab. 2). Observou-se valores decrescentes dos números de indivíduos nas classes de maiores diâmetro, com $56 \%$ dos indivíduos vivos amostrados pertencendo à primeira classe (Fig. 1). Cerca de 60\% destes indivíduos são de espécies do subosque, que, em geral, são de pequeno porte e o restante são de espécies do dossel, que em sua maioria são jovens. As espécies de subosque apresentaram indivíduos com diâmetro de no máximo $30 \mathrm{~cm}$. Como as principais espécies da comunidade estavam representadas nas várias classes de diâmetro,

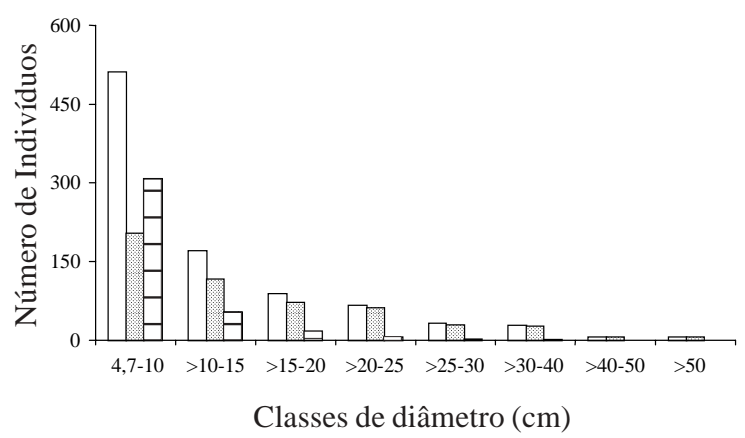

Figura 1. Distribuição em classes de diâmetro dos indivíduos amostrados na área alagável do Parque Estadual Mata dos Godoy, Londrina, PR. $\square$ - todas as espécies; 圈 espécies do dossel; $\boxminus$ - espécies do subosque. pode-se sugerir que esta comunidade, nas condições atuais, apresenta bom potencial de regeneração.

Os indivíduos amostrados apresentaram, na maior parte, alturas entre 4 e $12 \mathrm{~m}$ (Fig. 2) e os maiores que $18 \mathrm{~m}$ podem ser considerados como emergentes (Acacia polyphylla, Luehea divaricata e Ruprechtia laxiflora). A densidade de copas é alta na faixa de 4 a $12 \mathrm{~m}$, embora ocorra grande heterogeneidade de cobertura vegetal, havendo parcelas que recebem luz diretamente, enquanto outras são totalmente sombreadas (Bianchini et al. 2001).

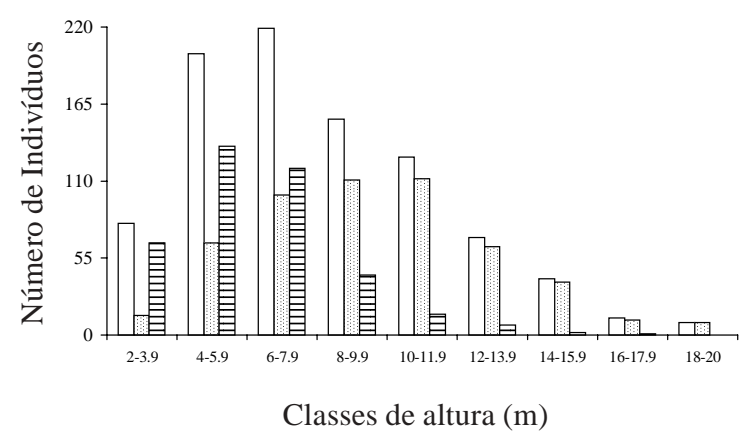

Figura 2. Distribuição em classes de altura dos indivíduos amostrados na área alagável do Parque Estadual Mata dos Godoy, Londrina, PR. $\square$ - todas as espécies; $:$ - espécies do dossel; $\boxminus$ - espécies do subosque. 
Tabela 2. Dados comparativos entre os quatro levantamentos efetuados no Parque Estadual Mata dos Godoy, Londrina, PR.

\begin{tabular}{lcccc}
\hline & Área alagável & Floresta ciliar & Espigão $^{2}$ & Encosta $^{3}$ \\
\hline Área (ha) & 0,5 & 0,6 & 1,0 & 0,6 \\
Densidade (n. ha ${ }^{-1}$ ) & 1.824 & 1.935 & 1.417 & 945 \\
Indivíduos amostrados mortos em pé & 58 & 25 & - & 21 \\
Número de famílias & 26 & 35 & 36 & 34 \\
Número de gêneros & 49 & 71 & 63 & 64 \\
Número de espécies & 64 & 96 & 100 & 83 \\
\% de espécies amostradas com um indivíduo & 24 & 29 & 25 & 22 \\
Índice de Diversidade de Shannon - H' & 3,44 & 3,90 & 3,69 & 3,69 \\
\hline
\end{tabular}

1 - Soares-Silva et al. (1998); 2 - Soares-Silva \& Barroso (1992); 3 - Silveira (1993)

Embora não seja possível definir os estratos da floresta, pode-se verificar que os indivíduos das espécies de dossel são mais abundantes entre 8 e $12 \mathrm{~m}$ e os das espécies de subosque entre $4 \mathrm{e}$ $8 \mathrm{~m}$ de altura (Fig. 2). O dossel é caracterizado, principalmente, por indivíduos de Nectandra megapotamica, Chrysophyllum gonocarpum, Ruprechtia laxiflora, Campomanesia xanthocarpa, Lonchocarpus campestris e Sebastiania commersoniana, e o subosque por indivíduos de Actinostemon concolor, Trichilia catigua, T. elegans, Bauhinia longifolia e diversas espécies de Eugenia.

$\mathrm{Na}$ área alagável, a floresta é mais baixa que no ambiente ciliar (Soares-Silva et al. 1998), cujo dossel encontra-se entre $12-20 \mathrm{~m}$, com árvores emergentes com até $40 \mathrm{~m}$. Possivelmente o grande número de indivíduos de baixa estatura na área alagável esteja relacionado à instabilidade do solo durante períodos de inundação e à pequena profundidade do sistema de raízes em razão da superficialidade do lençol freático. Estas características ampliam a possibilidade de tombamento dos indivíduos mais altos e limita o crescimento em altura de outros (Martinez-Ramos 1985).

A família Leguminosae apresentou o maior número de espécies (11), sendo seguida por Myrtaceae (10), Euphorbiaceae e Meliaceae (5) e Lauraceae (4), e estas famílias responderam por $55 \%$ do número total de espécies. Essas famílias também foram as que apresentaram o maior número de espécies na floresta ciliar (Soares-Silva et al. 1998), e na floresta da porção norte do Parque (Soares-Silva \& Barroso 1992), porém não na mesma ordem. Rodrigues \& Naves (2000) relacionaram Leguminosae, Myrtaceae, Rubiaceae, Lauraceae, Melastomataceae e Euphorbiaceae como as famílias mais importantes em florestas ciliares e, juntas, responderam por $44 \%$ do total das espécies amostradas. Observou-se que $60,8 \%$ dos indivíduos pertenceram às cinco famílias mais importantes da área. Estes resultados, em geral, são similares aos da floresta ciliar do PEMG (Soares-Silva et al. 1998) e apresentam maiores diferenças florísticas quando comparados à floresta da porção norte (Soares-Silva \& Barroso 1992). Cerca de $61 \%$ das famílias da área alagável foram representadas por apenas uma espécie (Tab. 1). Algumas dessas famílias como, por exemplo, Achatocarpaceae (Achatocarpus pubescens), são de pouca expressão regional e são representadas por espécies com pequeno número de indivíduos, enquanto outras, por exemplo, Apocynaceae (Tabernaemontana catharinensis), são importantes famílias nas florestas estacionais do Paraná e suas espécies, em geral, apresentam grande número de indivíduos.

Alta riqueza em gêneros foi observada na área alagável, pois $83,7 \%$ dos gêneros são 
representados por somente uma espécie. Eugenia (5), Trichilia (4), Campomanesia e Ocotea (3) apresentaram o maior número de espécies. Essa riqueza é similar à da floresta ciliar e menor que a da floresta da porção norte.

Foram amostradas 64 espécies na área alagável com alto índice de equabilidade $\left(J^{\prime}=0,82\right)$, indicando que não houve o predomínio de uma ou de poucas espécies sobre as outras. A razão do VI entre a primeira e a décima espécie (Tab. 3) foi de 1,83 para essa área, de 2,92 para a floresta ciliar, de 3,81 para a floresta da porção norte do PEMG e de 5,6 para a floresta ciliar da várzea do rio Bitumirim, o que comprova a maior equabilidade entre suas espécies. A comunidade da área alagável apresentou menor índice de diversidade de Shannon $\left(H^{\prime}=3,44\right)$ quando comparado aos de outras áreas do Parque (Tab. 2). Provavelmente o alagamento é o responsável por esta menor diversidade, pois é o único fator que claramente distingue esta área da floresta ciliar estudada por Soares-Silva et al. (1998). Este resultado está de acordo com informações de que áreas sujeitas a inundações periódicas ou esporádicas possuem menor diversidade que a floresta ciliar (Joly 1991), embora se deva considerar as diferenças metodológicas empregadas em cada estudo e o tamanho da área amostral.

Apesar da diversidade da área alagável ter sido inferior às outras amostragens no Parque, ela pode ser considerada alta se comparada com o estudo realizado na várzea do rio Bitumirim (Silva et al. 1992), cujo H' foi de 2,12. Possivelmente, a maior diversidade observada na área alagável do PEMG esteja relacionada às diferenças na frequiência e duração das inundações. $\mathrm{Na}$ várzea do rio Bitumirim as inundações são periódicas (anuais) e com duração superior a um mês (Silva et al. 1992) e no PEMG, as inundações são esporádicas ocorrendo, geralmente, em intervalos supraanuais e com duração de uma ou duas semanas. Sendo assim, o estresse provocado pelo alagamento é menos intenso no PEMG o que, possivelmente, promove maior diversidade de microsítios, por isso, favorece a ocorrência de maior número de espécies.

Comparando-se a área alagável com a floresta ciliar verificou-se que 48 espécies são comuns, 16 só ocorrem na primeira e 48 só ocorrem na segunda, resultando em similaridade da ordem de $40 \%$, sendo a maior entre as analisadas (Fig. 3). Era esperado maior similaridade entre estas áreas, visto que existe sobreposição parcial entre elas. No entanto, no estudo da floresta ciliar (Soares-Silva et al. 1998) foram amostradas áreas com influência direta do alagamento e áreas mais elevadas, não influenciadas diretamente, onde espécies intolerantes a este estresse estabelecem-se. Esta maior heterogeneidade ambiental da floresta ciliar responde, em parte, pela diferença florística observada em relação à área alagável. Quanto à menor similaridade da área alagável com a porção norte (Fig. 3), é possível que, além do alagamento, diferenças de temperatura e de tipos de solo podem estar determinando as diferenças florísticas. Apesar da ocorrência de espécies comuns entre a área aqui estudada e a várzea do rio Bitumirim (Fig. 3), o que demonstra ampla distribuição de espécies de regiões alagáveis (e. g. Sebastiania commersoniana), encontrou-se baixa similaridade entre essas áreas. Além da freqüência e duração das inundações, a latitude pode estar relacionada com esta baixa similaridade. No caso específico de áreas alagáveis, verificou-se que Chrysophyllum gonocarpum é uma espécie importante na região norte do Paraná, enquanto que na região sul, ela não aparece nos levantamentos. Estas informações são relevantes para projetos de recomposição de áreas alagáveis, pois diferenças regionais devem ser consideradas. Ressalta-se, oportunamente, que Rodrigues \& Naves (2000) encontraram baixa similaridade entre remanescentes florestais ciliares, mesmo entre aqueles próximos.

Foi observado que 26 espécies $(38,8 \%)$ apresentaram dez ou mais indivíduos, 25 (37,3\%) 
Tabela 3. Descritores fitossociológicos das espécies arbóreas da área alagável do Parque Estadual Mata dos Godoy, Londrina, PR, apresentados em ordem decrescente de VI. NI - número de indivíduos; DR - densidade relativa; DoR dominância relativa; FR - frequiência relativa; VI - valor de importância; VC - valor de cobertura; ES - estrato (D - dossel; $\mathrm{S}$ - subosque; E - emergente); CS - categoria sucessional (T - tolerante; I - intolerante à sombra).

\begin{tabular}{|c|c|c|c|c|c|c|c|c|}
\hline Espécie & NI & DR & DoR & FR & VI & $\mathrm{VC}$ & ES & CS \\
\hline Nectandra megapotamica & 71 & 7,32 & 5,54 & 6,86 & 19,72 & 12,86 & D & $\mathrm{T}$ \\
\hline Mortas & 58 & 5,98 & 6,69 & 6,52 & 19,19 & 12,67 & - & - \\
\hline Chrysophyllum gonocarpum & 44 & 4,54 & 8,23 & 4,97 & 17,74 & 12,77 & $\mathrm{D}$ & $\mathrm{T}$ \\
\hline Actinostemon concolor & 100 & 10,31 & 2,44 & 4,80 & 17,55 & 12,75 & $\mathrm{~S}$ & $\mathrm{~T}$ \\
\hline Ruprechtia laxiflora & 36 & 3,71 & 8,23 & 3,43 & 15,37 & 11,94 & $\mathrm{D}$ & I \\
\hline Trichilia catigua & 67 & 6,91 & 2,16 & 5,49 & 14,56 & 9,07 & $\mathrm{~S}$ & $\mathrm{~T}$ \\
\hline Campomanesia xanthocarpa & 40 & 4,12 & 5,22 & 4,80 & 14,14 & 9,34 & $\mathrm{D}$ & $\mathrm{T}$ \\
\hline Lonchocarpus campestris & 44 & 4,54 & 4,68 & 4,46 & 13,68 & 9,22 & $\mathrm{D}$ & I \\
\hline Sebastiania commersoniana & 27 & 2,78 & 6,31 & 2,74 & 11,84 & 9,10 & $\mathrm{D}$ & I \\
\hline Trichilia elegans & 52 & 5,36 & 0,98 & 4,46 & 10,80 & 6,34 & $\mathrm{~S}$ & $\mathrm{~T}$ \\
\hline Cupania vernalis & 27 & 2,78 & 4,39 & 3,09 & 10,26 & 7,18 & $\mathrm{D}$ & $\mathrm{T}$ \\
\hline Matayba elaeagnoides & 24 & 2,47 & 4,08 & 3,26 & 9,81 & 6,55 & $\mathrm{D}$ & $\mathrm{T}$ \\
\hline Alseis floribunda & 29 & 2,99 & 3,13 & 3,60 & 9,72 & 6,12 & $\mathrm{D}$ & I \\
\hline Lonchocarpus muehlbergianus & 29 & 2,99 & 2,98 & 2,74 & 8,71 & 5,97 & $\mathrm{E}$ & I \\
\hline Tabernaemontana catharinensis & 38 & 3,92 & 3,20 & 1,37 & 8,49 & 7,12 & $\mathrm{D}$ & I \\
\hline Machaerium paraguariense & 24 & 2,47 & 3,69 & 2,23 & 8,40 & 6,17 & $\mathrm{D}$ & $\mathrm{T}$ \\
\hline Acacia polyphylla & 11 & 1,13 & 3,97 & 1,37 & 6,48 & 5,10 & $\mathrm{D}$ & I \\
\hline Bauhinia longifolia & 23 & 2,37 & 1,39 & 2,23 & 5,99 & 3,76 & $\mathrm{~S}$ & I \\
\hline Eugenia repanda & 24 & 2,47 & 0,85 & 2,57 & 5,89 & 3,32 & $\mathrm{~S}$ & $\mathrm{~T}$ \\
\hline Machaerium stipitatum & 12 & 1,24 & 2,29 & 1,54 & 5,07 & 3,53 & $\mathrm{D}$ & $\mathrm{T}$ \\
\hline Chrysophyllum marginatum & 11 & 1,13 & 1,58 & 1,54 & 4,25 & 2,71 & $\mathrm{D}$ & $\mathrm{T}$ \\
\hline Parapiptadenia rigida & 10 & 1,03 & 1,66 & 1,54 & 4,23 & 2,69 & $\mathrm{E}$ & $\mathrm{T}$ \\
\hline Eugenia uniflora & 12 & 1,24 & 0,73 & 1,89 & 3,85 & 1,97 & $\mathrm{~S}$ & $\mathrm{~T}$ \\
\hline Casearia sylvestris & 10 & 1,03 & 1,25 & 1,54 & 3,82 & 2,28 & $\mathrm{D}$ & I \\
\hline Simira corumbaensis & 13 & 1,34 & 0,86 & 1,54 & 3,75 & 2,21 & $\mathrm{~S}$ & $\mathrm{~T}$ \\
\hline Allophylus guaraniticus & 14 & 1,44 & 0,41 & 1,89 & 3,74 & 1,86 & $\mathrm{~S}$ & I \\
\hline Campomanesia guavirova & 2 & 0,21 & 2,63 & 0,34 & 3,18 & 2,84 & $\mathrm{D}$ & $\mathrm{T}$ \\
\hline Balfourodendron riedelianum & 9 & 0,93 & 0,66 & 1,54 & 3,13 & 1,59 & $\mathrm{E}$ & $\mathrm{T}$ \\
\hline Guarea macrophylla & 9 & 0,93 & 0,59 & 1,37 & 2,89 & 1,52 & $\mathrm{~S}$ & $\mathrm{~T}$ \\
\hline Strychnos brasiliensis & 10 & 1,03 & 0,46 & 1,37 & 2,86 & 1,49 & $\mathrm{~S}$ & I \\
\hline Luehea divaricata & 1 & 0,10 & 2,20 & 0,17 & 2,47 & 2,30 & $\mathrm{D}$ & I \\
\hline Picramnia ramiflora & 10 & 1,03 & 0,22 & 1,03 & 2,28 & 1,25 & $\mathrm{~S}$ & $\mathrm{~T}$ \\
\hline Eugenia neoverrucosa & 8 & 0,82 & 0,31 & 1,03 & 2,16 & 1,13 & $\mathrm{~S}$ & $\mathrm{~T}$ \\
\hline Holocalyx balansae & 8 & 0,82 & 0,47 & 0,86 & 2,15 & 1,29 & $\mathrm{D}$ & $\mathrm{T}$ \\
\hline Pouteria beaurepairei & 5 & 0,52 & 0,27 & 0,86 & 1,64 & 0,78 & $\mathrm{~S}$ & I \\
\hline Plinia rivularis & 4 & 0,41 & 0,46 & 0,51 & 1,39 & 0,87 & $\mathrm{~S}$ & $\mathrm{~T}$ \\
\hline Campomanesia guazumifolia & 3 & 0,31 & 0,73 & 0,34 & 1,38 & 1,04 & $\mathrm{~S}$ & $\mathrm{~T}$ \\
\hline Eugenia cf. moraviana & 5 & 0,52 & 0,12 & 0,69 & 1,33 & 0,64 & $\mathrm{~S}$ & $\mathrm{~T}$ \\
\hline Eugenia ramboi & 4 & 0,41 & 0,15 & 0,69 & 1,25 & 0,57 & $\mathrm{~S}$ & $\mathrm{~T}$ \\
\hline Sorocea bonplandii & 4 & 0,41 & 0,12 & 0,69 & 1,22 & 0,54 & $\mathrm{~S}$ & $\mathrm{~T}$ \\
\hline Bougainvillea spectabilis & 3 & 0,31 & 0,35 & 0,51 & 1,17 & 0,65 & $\mathrm{D}$ & $\mathrm{T}$ \\
\hline Terminalia $\mathrm{sp}$. & 3 & 0,31 & 0,18 & 0,51 & 1,01 & 0,49 & $\mathrm{D}$ & $\mathrm{T}$ \\
\hline Sapium glandulatum & 2 & 0,21 & 0,39 & 0,34 & 0,94 & 0,60 & $\mathrm{~S}$ & I \\
\hline Ocotea dyospirifolia & 1 & 0,10 & 0,55 & 0,17 & 0,82 & 0,65 & $\mathrm{D}$ & $\mathrm{T}$ \\
\hline Ocotea puberula & 2 & 0,21 & 0,27 & 0,34 & 0,81 & 0,47 & $\mathrm{D}$ & $\mathrm{T}$ \\
\hline Phytolacca dioica & 1 & 0,10 & 0,49 & 0,17 & 0,76 & 0,59 & $\mathrm{D}$ & I \\
\hline Myrocarpus frondosus & 2 & 0,21 & 0,16 & 0,34 & 0,71 & 0,37 & D & $\mathrm{T}$ \\
\hline
\end{tabular}


Tabela 3 (continuação)

\begin{tabular}{lcccccccc}
\hline Espécie & NI & DR & DoR & FR & VI & VC & ES & CS \\
\hline Trichilia clausseni & 2 & 0,21 & 0,12 & 0,34 & 0,67 & 0,33 & S & T \\
Boehmeria caudata & 3 & 0,31 & 0,15 & 0,17 & 0,63 & 0,46 & S & I \\
Ocotea indecora & 2 & 0,21 & 0,07 & 0,34 & 0,62 & 0,28 & S & I \\
Banara tomentosa & 2 & 0,21 & 0,05 & 0,34 & 0,60 & 0,25 & S & T \\
Alchornea triplinervia & 1 & 0,10 & 0,29 & 0,17 & 0,57 & 0,39 & D & I \\
Achatocarpus pubescens & 2 & 0,21 & 0,16 & 0,17 & 0,54 & 0,36 & S & T \\
Croton floribundus & 1 & 0,10 & 0,10 & 0,17 & 0,38 & 0,20 & D & I \\
Myrsine aff. loefgrenii & 1 & 0,10 & 0,09 & 0,17 & 0,36 & 0,19 & $\mathrm{~S}$ & $?$ \\
Vassobia breviflora & 1 & 0,10 & 0,09 & 0,17 & 0,36 & 0,19 & $?$ & $?$ \\
Patagonula americana & 1 & 0,10 & 0,03 & 0,17 & 0,31 & 0,14 & $\mathrm{E}$ & $\mathrm{T}$ \\
Myrciaria floribunda & 1 & 0,10 & 0,03 & 0,17 & 0,31 & 0,14 & $\mathrm{~S}$ & $\mathrm{I}$ \\
Trichilia casaretti & 1 & 0,10 & 0,02 & 0,17 & 0,30 & 0,13 & $\mathrm{~S}$ & $\mathrm{~T}$ \\
Sloanea monosperma & 1 & 0,10 & 0,02 & 0,17 & 0,29 & 0,12 & $\mathrm{D}$ & $\mathrm{T}$ \\
Casearia decandra & 1 & 0,10 & 0,02 & 0,17 & 0,29 & 0,12 & $\mathrm{~S}$ & $\mathrm{~T}$ \\
Dalbergia frutescens & 1 & 0,10 & 0,02 & 0,17 & 0,29 & 0,12 & $\mathrm{~S}$ & $\mathrm{I}$ \\
Justicia brasiliana & 1 & 0,10 & 0,01 & 0,17 & 0,29 & 0,11 & $\mathrm{~S}$ & $\mathrm{I}$ \\
Pisonia aculeata & 1 & 0,10 & 0,01 & 0,17 & 0,28 & 0,11 & $\mathrm{~S}$ & $\mathrm{~T}$ \\
Inga marginata & 1 & 0,10 & 0,01 & 0,17 & 0,28 & 0,11 & $\mathrm{~S}$ & $\mathrm{~T}$ \\
\hline
\end{tabular}

apresentaram entre dois a nove e $16(24 \%)$ apresentaram apenas um indivíduo (Tab. 2 e 3), estando abaixo dos valores descritos na literatura (Durigan et al. 2000; Oliveira et al. 2001). Provavelmente, as espécies com apenas um indivíduo encontram baixo número de microsítios favoráveis à sua regeneração, estando o alagamento possivelmente envolvido na

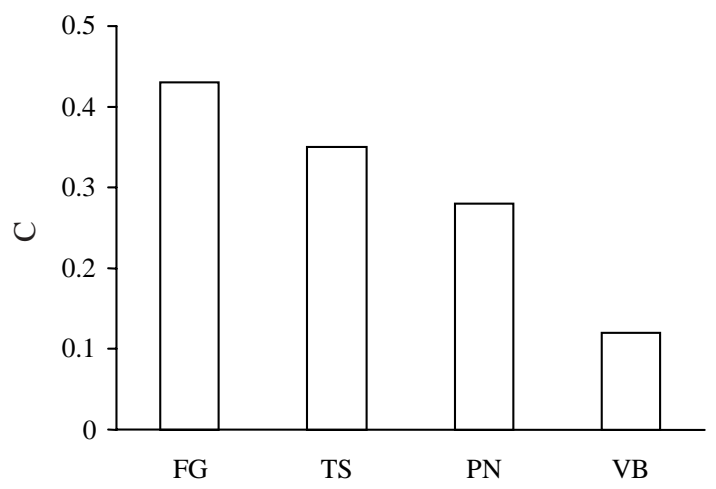

Figura 3. Similaridade florística da área alagável com a floresta de galeria (FG), com a floresta de toposeqüência (TS), com a floresta da porção norte (PN) do Parque Estadual Mata dos Godoy, Londrina, PR e com a floresta da várzea do rio Bitumirim (VB), Ipiranga, PR. C - índice de similaridade de Jaccard. definição destes sítios. A luz também pode estar envolvida, como sugerido por Oliveira et al. (2001). Dentre as espécies amostradas, Actinostemon concolor apresentou a maior densidade $(10,3 \%$ do total), seguida por Nectandra megapotamica $(7,3 \%)$. A DR das dez primeiras espécies em VI e as árvores mortas correspondem a $52 \%$ e $6 \%$ do total respectivamente (Tab. 3 ).

Considerando as 26 espécies com dez ou mais indivíduos, verificou-se que $57,7 \%$ são de dossel, 7,7 \% são emergentes e $34,6 \%$ são de subosque (Tab. 3). Segundo informações obtidas de Silva \& Soares-Silva (2000), 58\% e $42 \%$ dessas espécies são tolerantes e intolerantes à sombra, respectivamente (Tab. 3), sendo estes valores similares aos obtidos para a floresta ciliar. Em relação à floresta da porção norte observou-se, na área alagável, maior participação das intolerantes no conjunto de espécies amostradas. Possivelmente, isto está relacionado à calha do rio, que favorece a ação dos ventos e produz efeito de borda. Por estas razões, as perturbações naturais como, por exemplo, quebra de copas, podem ser mais 
frequientes na área próxima ao rio, o que está de acordo com as observações de Bianchini et al. (2001). Além disto, a presença do ribeirão e a fisionomia da vegetação na margem oposta a do Parque (capoeira) possibilitam maior incidência de luz na área alagável, o que favorece as espécies intolerantes à sombra.

Nectandra megapotamica apresentou o maior valor de importância (Tab. 3), sendo a espécie mais freqüente (presente em $80 \%$ das unidades amostrais), com a quarta maior DoR e a segunda maior DR. Na floresta de galeria $N$. megapotamica também foi a espécie mais importante, enquanto que na porção norte do Parque ela ocupou a quinta posição em VI. Esses resultados sugerem que essa espécie apresenta ampla tolerância ecológica, permitindo que a mesma seja mais dispersa no Parque. Segundo Lorenzi (1992), N. megapotamica não tem preferência definida por tipo de solo e apresenta ampla dispersão pela floresta ombrófila, o que está de acordo com os resultados aqui descritos para a floresta estacional semidecidual.

As árvores mortas ocuparam posição de destaque no levantamento (Tab. 2 e 3), similar ao observado em outros levantamentos realizados nas florestas ciliares da bacia do rio Tibagi (Silva et al. 1992; 1995; Soares-Silva et al. 1992; Dias et al. 1998). Em geral, foram indivíduos de grande porte que morreram (DoR alta) e as mortes ocorreram na área como um todo (FR alta). Considerando a variação em altura de elementos de uma espécie, é esperado que os indivíduos maduros de maior tamanho se tornem senis, percam a vitalidade e acabem morrendo em pé. Deve-se salientar, entretanto, que esta categoria inclui elementos de várias espécies e tamanhos (jovens e adultos), sugerindo que várias podem ser as causas de morte, como patogenia, herbivoria, competições intra e interespecíficas e perturbações no ambiente. As plantas mortas podem interferir no processo de regeneração da vegetação através da abertura de clareiras (formadas pela queda destes indivíduos), o que pode alterar a proporção de espécies tolerantes e intolerantes à sombra na comunidade. Comparando-se o número de indivíduos mortos na área alagável com os menores números amostrados nos demais levantamentos realizados no PEMG (Tab. 2), sugere-se que o alagamento e suas conseqüências estejam entre os importantes fatores responsáveis pela maior mortalidade.

Chrysophyllum gonocarpum apresentou o terceiro maior VI na área alagável (Tab. 3), o sétimo maior VI na floresta de galeria e o décimo quarto na porção norte do PEMG. Estes resultados e os de Bianchini (1998) indicam que a espécie apresenta tolerância relativa ao alagamento, tendo preferência por habitats com inundações esporádicas. Segundo Lorenzi (1992), C. gonocarpum é irregularmente distribuída em fundo de vales e início de encostas e em terrenos planos, onde o solo contém maior teor de umidade.

Actinostemon concolor apresentou o quarto maior VI na floresta alagável (Tab. 3), o terceiro na floresta de galeria, o oitavo na porção norte e o maior VI na várzea do rio Bitumirim (Silva et al. 1992), caracterizando-se como uma importante espécie das florestas da bacia do rio Tibagi. Estes resultados indicam que a espécie apresenta ampla faixa de tolerância às condições do ambiente. Entretanto, sua densidade é maior nas áreas alagáveis, indicando que suas estratégias de vida são mais efetivas nestas áreas.

Ruprechtia laxiflora, Trichilia catigua, Campomanesia xanthocarpa, Lonchocarpus campestris, Sebastiania commersoniana e Trichilia elegans completam a lista das dez espécies com maiores valores de VI na área alagável (Tab. 3). Estas espécies, quando presentes, tiveram menores valores de VI para a floresta ciliar e para a floresta da porção norte do Parque, sugerindo que as estratégias de vida, destas espécies são mais efetivas nas áreas que sofrem influência direta dos rios. $R$. laxiflora, L. campestris e $S$. commersoniana não ocorrem na porção norte do Parque, o que 
reforça a sugestão anterior. Em estudos sobre tolerância à inundação, S. commersoniana (Kolb et al. 1998) e C. xanthocarpa (Pimenta 1998) foram consideradas tolerantes.

Dentre as nove espécies com os maiores VIs, três grupos podem ser definidos: grupo 1 espécies de dossel e tolerantes à sombra; grupo 2 - espécies de dossel e intolerantes à sombra; grupo 3 - espécies de subosque e tolerantes à sombra (Tab. 3). Três espécies pertencem ao primeiro grupo (Nectandra megapotamica, Chrysophyllum gonocarpum e Campomanesia xanthocarpa) e apresentaram declínio no número de indivíduos nas classes de maior diâmetro, caracterizando curvas exponenciais negativas (Fig. 4). As curvas indicam que estas espécies estão se regenerando na área e que, caso não ocorram bruscas alterações no ambiente, se manterão como importantes na estrutura da comunidade. As espécies do grupo 1 apresentam padrão espacial aleatório (Tab. 4), não sendo possível detectar algum fator do ambiente que possa interferir no estabelecimento destas espécies na área estudada.

No grupo 2, são enquadradas três espécies (Ruprechtia laxiflora, Lonchocarpus campestris e Sebastiania commersoniana), sendo que somente L. campestris apresentou estrutura de tamanho caracterizada por uma

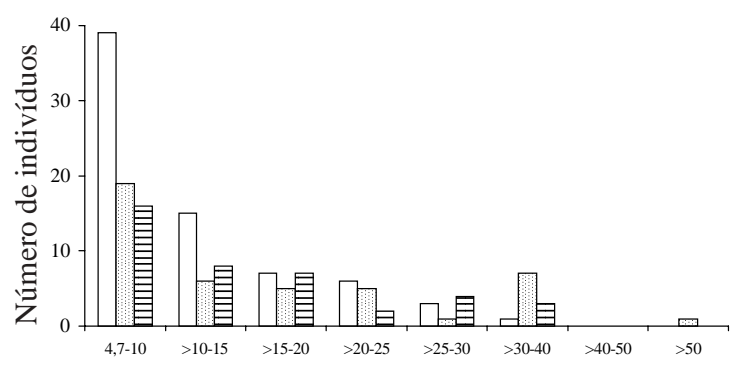

Classes de diâmetro

Figura 4. Classes de diâmetro de espécies arbóreas da área alagável do Parque Estadual Mata dos Godoy, Londrina, PR. $\square$ - Nectandra megapotamica;. - Chrysophyllum gonocarpum; $\boxminus$ - Campomanesia xanthocarpa. curva exponencial negativa (Fig. 5). No entanto, a maioria dos indivíduos de $R$. laxiflora e $S$. commersoniana está concentrada nas duas primeiras classes de diâmetro (Fig. 5). As estruturas de tamanho destas três espécies indicam que elas se regeneram nesta área. Estas espécies apresentaram padrão espacial agregado (Tab. 4), possivelmente tendo a luz como fator determinante. Bianchini et al. (2001) observaram grande heterogeneidade no índice de cobertura do dossel desta área, resultante da maior probabilidade de perturbações, o que possivelmente está relacionado à regeneração destas espécies em sítios perturbados (clareiras). Deve-se mencionar que o alagamento também pode estar relacionado ao padrão espacial agregado apresentado pelos indivíduos de $S$. commersoniana, tendo em vista sua tolerância ao alagamento (Kolb et al. 1998) e sua importância em áreas alagáveis (Silva et al. 1992).

Três espécies pertencem ao grupo 3 (Actinostemon concolor, Trichilia catigua e T. elegans) e todas apresentaram a maioria dos indivíduos na primeira classe e com brusca redução do número nas classes seguintes (Fig. 6). Elas apresentaram indivíduos com diâmetros menores que $25 \mathrm{~cm}$, comprovando serem típicas do subosque. Estas espécies apresentaram padrão espacial fortemente

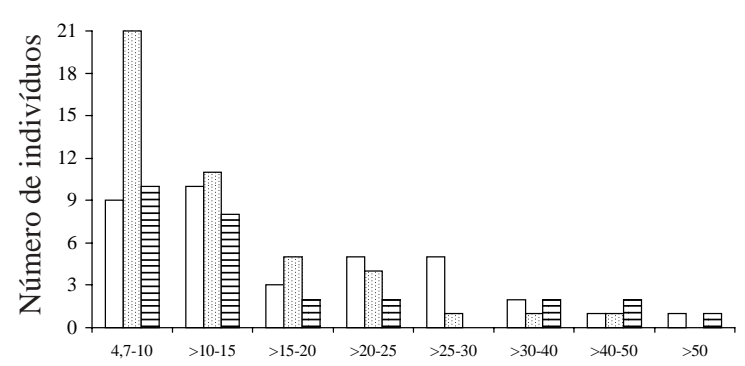

Classes de diâmetro

Figura 5. Classes de diâmetro de espécies arbóreas da área alagável do Parque Estadual Mata dos Godoy, Londrina, PR. $\square$ - Ruprechtia laxiflora; : Lonchocarpus campestris; $\boxminus$-Sebastiania commersoniana. 
agregado (Tab. 4), ocorrendo preferencialmente nas parcelas com nenhum ou poucos sinais de perturbação, como troncos caídos, grande número de lianas e presença de indivíduos jovens de espécies pioneiras. O padrão agregado pode estar relacionado a uma distribuição mais localizada de microsítios favoráveis ao estabelecimento de plântulas e de plantas jovens (Bleher \& Böhning-Gaese 2001).

Foram amostradas 64 espécies arbóreas na área alagável do Parque Estadual Mata dos Godoy e, esta comunidade, apresenta estrutura que difere das demais áreas estudadas do Parque. Embora seja alta a similaridade das espécies entre a área alagável e a floresta ciliar, as estruturas das duas áreas apresentaram diferenças que, certamente, estão relacionadas com o alagamento e suas conseqüências. A menor diversidade da área alagável comparada às outras áreas, reflete a seletividade que o ambiente impõe, sendo que as espécies mais adaptadas tornam-se dominantes e contribuem para o estabelecimento da estrutura que caracteriza esta comunidade. A análise da estrutura de tamanho das principais espécies da área sugere que esta comunidade arbórea se manterá sem grandes mudanças na sua estrutura, desde que não ocorram bruscas alterações ambientais.

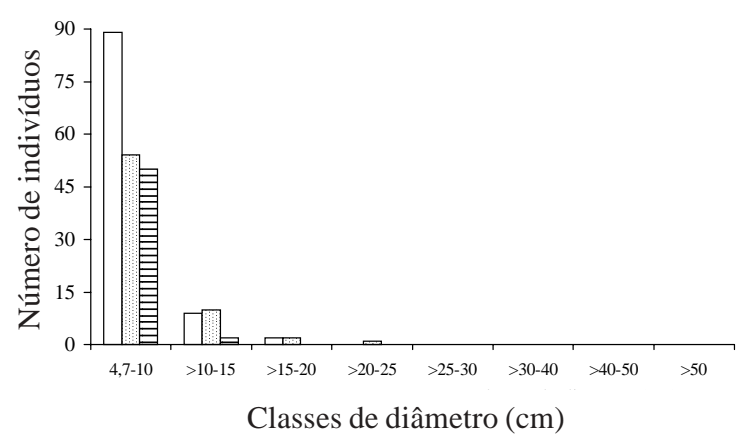

Figura 6. Classes de diâmetro de espécies arbóreas da área alagável do Parque Estadual Mata dos Godoy, Londrina, PR. $\square$-Actinostemon concolor; 圈 - Trichilia catigua; $\boxminus-$ T. elegans.
Tabela 4. Coeficiente de dispersão (CD) e padrão de distribuição espacial das nove espécies com maiores valores de importância na área alagável do Parque Estadual Mata dos Godoy, Londrina, PR. * - difere significativamente de 1,0 ao nível de $5 \%$ de probabilidade pelo teste t.

\begin{tabular}{lll}
\hline Espécie & $\mathrm{CD}$ & $\begin{array}{c}\text { Padrão } \\
\text { espacial }\end{array}$ \\
\hline Nectandra megapotamica & 1,04 & aleatório \\
Chrysophyllum gonocarpum & 1,00 & aleatório \\
Actinostemon concolor & $5,82^{*}$ & agregado \\
Ruprechtia laxiflora & $2,72^{*}$ & agregado \\
Trichilia catigua & $2,15^{*}$ & agregado \\
Campomanesia xanthocarpa & 0,92 & aleatório \\
Lonchocarpus campestris & $1,84^{*}$ & agregado \\
Sebastiania commersoniana & $2,13^{*}$ & agregado \\
Trichilia elegans & $2,47^{*}$ & agregado \\
\hline
\end{tabular}

\section{Agradecimentos}

Os autores agradecem ao Instituto Ambiental do Paraná, pela autorização de coleta no PEMG; ao Edson Mendes Francisco, pelo auxílio nos trabalhos de campo e a Marcos Sobral, pela identificação das mirtáceas.

\section{Referências bibliográficas}

Bianchini, E. 1998. Estudo da dinâmica de população de Chrysophyllum gonocarpum (Mart. \& Eichler) Engl. no Parque Estadual Mata dos Godoy, Londrina, PR. Tese de Doutorado, Universidade Estadual de Campinas, Campinas.

Bianchini, E.; Pimenta, J. A. \& Santos, F. A. M. 2001. Spatial and temporal variation in the canopy cover in a tropical semi-deciduous forest. Brazilian Archives of Biology and Technology, 44(3): 269-276.

Bleher, B. \& Böhning-Gaese, K. 2001. Consequences of frugivore diversity for seed dispersal, seedling establishment and the spatial pattern of seedlings and trees. Oecologia 129: 385-394.

Brower, J. E. \& Zar, J. H. 1984. Field \& laboratory methods for general ecology. $2 \mathrm{ed}$. Wm. C. Brown Publishers, Dubuque, Iowa.

Cronquist, A. 1981. An integrated system of classification of flowering plants. Columbia Univ. Press, New York. 
Dias, M. C.; Vieira, A. O. S.; Nakajima, J. N.; Pimenta, J. A. \& Lobo, P. C. 1998. Composição florística e fitossociologia do componente arbóreo das florestas ciliares do rio Iapó, na bacia do rio Tibagi, Tibagi, PR. Revista Brasileira de Botânica 21(2): 183-195.

Durigan, G.; Rodrigues, R. R. \& Schiavini, I. 2000. A heterogeneidade ambiental definindo a metodologia de amostragem da floresta ciliar. Pp. 159-167. In R. R. Rodrigues \& H. F. Leitão-Filho (eds.). Matas ciliares: conservação e recuperação. EDUSP, São Paulo.

Ferreira, L. V. \& Stohlgren, T. J. 1999. Effects of river level fluctuation on plant species richness, diversity, and distribution in a floodplain forest in Central Amazonia. Oecologia 120(4): 582-587.

Joly, C. A. 1991. Flooding tolerance in tropical trees. Pp. 23-34. In M. B. Jackson; D. D. Davis \& H. Lambers (eds.) Plant under oxygen deprivation. SPB Academic Publishing, The Hague.

Kolb, R. M.; Medri, M. E.; Bianchini, E.; Pimenta, J. A.; Giloni, P. C. \& Correa, G. T. 1998. Anatomia ecológica de Sebastiania commersoniana (Baillon) Smith \& Downs (Euphorbiaceae) submetida ao alagamento. Revista Brasileira de Botânica 21(3): 305-312.

Lorenzi, H. 1992. Árvores brasileiras. Plantarum, Nova Odessa.

Ludwig, J. A. \& Reynolds, J. F. 1988. Statistical ecology: a primer on methods and computing. John Wiley \& Sons, New York.

Martínez-Ramos, M. 1985. Claros, ciclos vitales de los árboles tropicales y regeneración natural de las selvas altas perenifolias. Pp. 191-239. In A. GomezPómpa \& S. R. Amo (eds.). Investigaciones sobre la regeneración de selvas altas en Veracruz, Mexico. Editorial Alhambra Mexicana, Mexico.

Mertes, L. A. K.; Daniel, D. L.; Melack, J. M.; Nelson, B.; Martinelli, L. A. \& Forsberg, B. R. 1995. Spatial patterns of hydrology, geomorphology and vegetation of flood plain of the Amazon River in Brazil from a remote sensing perspective. Geomorphology 13: 215-232.

Mori, S. A.; Silva, L. A. M.; Lisboa, G. \& Coradin, L. 1985. Manual de manejo de herbário fanerogâmico. CEPLAC, Ilhéus.

Mueller-Dombois, D. \& Ellenberg, H. A. 1974. Aims and methods of vegetation ecology. John Wiley, New York.
Nakajima, J. N.; Soares-Silva, L. H.; Medri, M. E.; Goldemberg, R. \& Correa, G. T. 1996. Composição florística e fitossociológica do componente arbóreo das florestas ciliares da bacia do rio Tibagi, Paraná: 6. Fazenda Monte Alegre, Telêmaco Borba, PR. Arquivos de Biologia e Tecnologia 39(4): 933-948.

Oliveira, R. J.; Mantovani, W. \& Melo, M. M. R. F. 2001. Estrutura do componente arbustivoarbóreo da floresta atlântica de encosta, Peruíbe, SP. Acta Botanica Brasilica 15(3): 391-412.

Pimenta, J. A. 1998. Estudo populacional de Campomanesia xanthocarpa O. Berg (Myrtaceae) no Parque Estadual Mata dos Godoy, Londrina, PR. Tese de Doutorado, Universidade Estadual de Campinas, Campinas.

Reitz, R. 1988. Euforbiáceas. In R. Reitz (ed.). Flora Ilustrada Catarinense. Herbário Barbosa Rodrigues, Itajaí.

Rodrigues, R. R. \& Leitão-Filho, H. F. 2000. Matas ciliares: conservação e recuperação. EDUSP, São Paulo.

Rodrigues, R. R. \& Nave, A. G. 2000. Heterogeneidade florística das matas ciliares. Pp. 45-71. In R. R. Rodrigues \& H. F. Leitão-Filho (eds.). Matas ciliares: conservação e recuperação. EDUSP, São Paulo,

Rodrigues, R. R. \& Shepherd, G. J. 2000. Fatores condicionantes da vegetação ciliar. Pp. 101-107. In R. R. Rodrigues \& H. F. Leitão-Filho (eds.). Matas ciliares: conservação e recuperação. EDUSP, São Paulo.

Salo, J.; Kalliola, R.; Hakkinen, J.; Mäkinen, Y; Niemela, P.; Puhakka, M. \& Coley, P. D. 1986. River dynamics and the diversity of Amazon lowland forest. Nature 322: 254-258.

Shepherd, G. J. 1996. Fitopac 1: manual do usuário. Departamento de Botânica, Universidade Estadual de Campinas.

Silva, F. C. \& Soares-Silva, L. H. 2000. Arboreal flora of the Godoy Forest State Park, Londrina, PR., Brazil. Edinburgh Journal of Botany 57(1): 107-120.

Silva, F. C.; Fonseca, E. P.; Soares-Silva, L. H.; Muller, C. \& Bianchini, E. 1995. Composição florística e fitossociologia do componente arbóreo das florestas ciliares da bacia do rio Tibagi. 3. Fazenda Bom Sucesso, município de Sapopema, PR. Acta Botanica Brasilica 9(2): 289-302. 
Silva, S. M.; Silva, F. C.; Vieira, A. O. S.; Nakajima, J. N.; Pimenta, J. A. \& Colli, S. 1992. Composição florística e fitossociologia do componente arbóreo das florestas ciliares da bacia do rio Tibagi, PR. 2. Várzea do Bitumirim, município de Ipiranga, PR. Pp. 192-198. In Anais do $2^{\circ}$ Congresso Nacional de Essências Nativas, São Paulo 1992. Instituto Florestal, São Paulo.

Silveira, M. 1993. Estudo da vegetação em uma toposequiência no Parque Estadual Mata dos Godoy, Londrina, Paraná. Dissertação de Mestrado. Universidade Federal do Paraná, Curitiba.

Soares-Silva, L. H. \& Barroso, G. M. 1992. Fitossociologia do estrato arbóreo da floresta na porção norte do Parque Estadual Mata dos Godoy, Londrina, Paraná, Brasil. Pp. 101-112. In Anais do $8^{\circ}$ Congresso SBPC, Campinas.
Soares-Silva, L. H.; Bianchini, E.; Fonseca, E. P.; Dias, M. C.; Medri, M. E. \& Zangaro Filho, W. 1992. Composição florística e fitossociologia do componente arbóreo das florestas ciliares da bacia do rio Tibagi. 1. Fazenda Doralice, Ibiporã, PR. Pp. 199-206. In Anais do $2^{\circ}$ Congresso Nacional de Essências Nativas, São Paulo 1992. Instituto Florestal, São Paulo.

Soares-Silva, L. H.; Kita, K. K. \& Silva, F. C. 1998. Fitossociologia de um trecho de floresta de galeria no Parque Estadual Mata dos Godoy, Londrina, PR, Brasil. Boletim do Herbário Ezechias Paulo Heringer 3: 46-62.

Stenvenson, P. R.; Castellanos, M. C. \& Medina, A. P. 1999. Elementos arboreos de los bosques de un plano inundable en el Parque Nacional Natural Tinigua, Colombia. Caldasia 21(1): 38-49. 